\title{
Identification of Multi-Cracks in the Gate Rotor Shaft Based on the Wavelet Finite Element Method
}

\author{
Bin Zhao \\ Department of Chemical Engineering Mechanics, \\ School of Mechanical Engineering, Liaoning Shihua University, Fushun, Liaoning, 113001, China
}

Received 2013-05-05, Revised 2013-06-26; Accepted 2013-09-12

\begin{abstract}
In order to have fault identification for the gate rotor shaft with multiple cracks effectively, the quantity identification method of the gate rotor shaft with multiple cracks based on wavelet finite element method is established and the frequency test of the gate rotor shaft based on blind source separation algorithm is analyzed. Firstly the wavelet finite element was established by combining the Daubechies wavelet theory and the traditional finite element theory and then the vibration equations of intact and cracked wavelet finite element were obtained, which were applied to compute the changing rate of the natural frequencies for the cracked gate rotor shaft. Then natural frequencies fitting curve surface of the cracked gate rotor shaft with were acquired based on the wavelet finite element method and the identification procedure of the cracks was confirmed and the gate rotor shaft with two different cracks was analyzed and the results showed that the wavelet finite element could predict the multi-cracks correctly.
\end{abstract}

Keywords: Gate Rotor Shaft, Wavelet Finite Element Method, Multiple Crack Identification

\section{INTRODUCTION}

Single screw compressors are used widely in petrochemical industry. It has the merits of small volume, light weight, reasonable structure, reliable running, low vibration and easy maintenance and it is an advanced forward-looking compression. The operation of a single-screw compressor can be divided into four phases: suction, sealing, compression and discharge. It is mainly made up of a gate rotor and a screw rotor. The gate rotor shaft is an important part of the single screw compressor, which rotates about axis of the gate rotor shaft during the working procession, which is shown in Fig. 1.

The gate rotor shaft and the gate rotor are fixed together by one or two pins with $\mathrm{O}$ shaped rubber ring. Due to the elastic of the $\mathrm{O}$ shaped rubber ring, the gate rotor can turn a little relative to the gate rotor shaft and the wear of the gate rotor can be avoided. The gate rotor shaft works under high rotational speed and temperature and the initial small crack will generate in the course of operation. With the growth of the crack, the teeth of the gate rotor shaft will be damaged. Therefore it is important to predict the crack of the gate rotor shaft and identify the relating parameters of the crack for the gate rotor shaft.

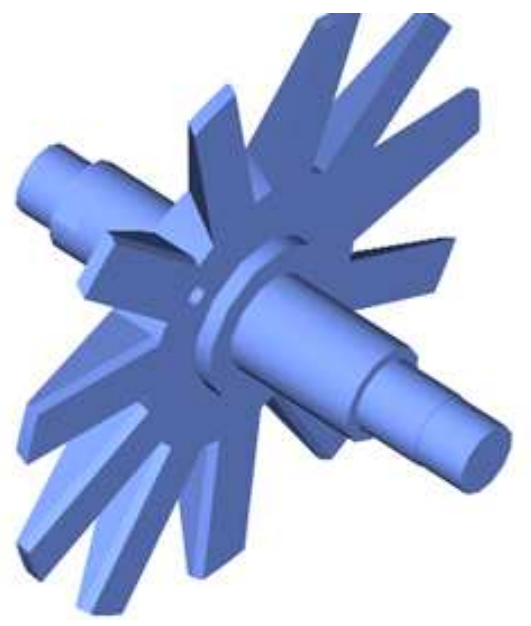

Fig. 1. The model of the gate rotor shaft 
When the crack of the structure generated, the local stiffness of the structure will decrease and the natural frequency of the structure will change. This characteristic of the structure is used in many recognizing technologies of the crack. However for the complex structure, traditional finite element method has difficulty in recognizing the crack precisely and some difficulties such as poor robustness, low computing efficient are not avoided. In order to get high calculating precise, a lot high dimensional elements should be applied.

The wavelet finite element is the outcome combining the multi-resolution property of wavelet with the traditional finite element method and using the wavelet function or scale function as interpolating function is a basic idea of the wavelet finite element method and covers the shortage of traditional finite element method solving the big gradient and strange problems. Wavelet finite element application has attracted many researchers in a wide variety of practical problems. The rotor-bearing systems was analyzed by a wavelet finite element method and the B-spline wavelet on the interval RayleighTimoshenko shaft element considering the shear deformation was investigated and the good performance of this method was demonstrated in the practical application and numerical examples (Xiang et al., 2009).

During the procession of failure of the structure, there is not only a crack existing in the structure. If the failure of the structure is unknown, the identification method of single crack is used to identify the damage of the structure blindly and some cracks can not be reported. Therefore, it is important to identify all the cracks in the structure. Because the quantity of unknown crack parameters is far more, the identification of the multiple cracks of the structure will be very complex. This research will identify the multiple cracks of the gate rotor shaft of the single screw compressor based on the wavelet finite element method with.

\section{THEORY MODEL OF THE GATE ROTOR SHAFT}

\subsection{Theory Model of Wavelet Analysis}

A series of orthogonal Daubechies wavelet with the character of muti-resolution analysis is established by Daubechies. The scale function of Daubechies wavelet $\varphi_{\mathrm{N}}(\mathrm{x})$ is expressed as Equation 1 (Chen et al., 2004):

$$
\varphi_{\mathrm{N}}(\mathrm{x})=\sum_{\mathrm{k}=0}^{\mathrm{N}-1} \mathrm{p}_{\mathrm{k}} \phi_{\mathrm{N}}(2 \mathrm{x}-\mathrm{k})
$$

where, $\mathrm{N}$ denotes the number of order, $\mathrm{p}_{\mathrm{k}}$ denotes the scale function coefficient, $\mathrm{k}=0,1, \ldots, \mathrm{N}-1$.

According to the scale function, the wavelet mother function $\psi_{\mathrm{N}}(\mathrm{x})$ is expressed in Equation 2:

$\psi_{\mathrm{N}}(\mathrm{x})=\sum_{\mathrm{k}=2-\mathrm{N}}^{1} \mathrm{q}_{\mathrm{k}} \phi_{\mathrm{N}}(2 \mathrm{x}-\mathrm{k})$

where, $\mathrm{q}_{\mathrm{k}}$ denotes the wavelet coefficient, $\mathrm{k}=0,1, . ., \mathrm{N}-1$.

Because the wavelet function is orthogonal to the scale function, the relationship between the scale function coefficients and the wavelet coefficients satisfies Equation 3:

$\mathrm{q}_{\mathrm{k}}=(-1)^{\mathrm{k}} \mathrm{p}_{1-\mathrm{k}}$

Daubechies wavelet functions $\phi^{1}(\varepsilon), \phi^{2}(\eta)$ and $\phi^{3}$ ( $\eta$ ) span the multi-resolution subspaces $\left\{V_{j}^{1}\right\},\left\{V_{j}^{2}\right\}$ and $\left\{\mathrm{V}_{\mathrm{j}}^{3}\right\}$, the tensor product of these subspaces forms the high-order subspace, which is expressed in Equation 4:

$V_{j}=V_{j}^{1} \otimes V_{j}^{2} \otimes V_{j}^{3}$

where, $\otimes$ denotes Kronecker signal.

$\left\{\mathrm{V}_{\mathrm{j}}\right\}$ forms the multi-resolution of the Hilbert space $\mathrm{L}^{2}$ $\left(\mathrm{R}^{2}\right)$, which is defined as Equation 5 to 7 (Liu et al., 2008):

$\vec{\varphi}^{1}=\left\{\phi^{1}(\xi), \phi^{1}(\xi+1), \ldots, \phi^{1}(\xi+(\mathrm{N}-2))\right\}$

$\vec{\varphi}^{2}=\left\{\phi^{2}(\eta), \phi^{2}(\eta+1), \ldots, \phi^{2}(\eta+(N-2))\right\}$

$\vec{\varphi}^{3}=\left\{\phi^{3}(\eta), \phi^{3}(\eta+1), \ldots, \phi^{3}(\eta+(N-2))\right\}$

The wavelet scale function in the space $\left\{\mathrm{V}_{\mathrm{j}}\right\}$ is expressed in Equation 8:

$\vec{\phi}=\vec{\phi}^{1} \otimes \vec{\phi}^{2} \otimes \vec{\phi}^{3}$

The calculation of the natural frequency for the gate rotor shaft with the multi-crack belongs to three dimension problem. When the natural frequency is calculated, the gate rotor shaft can be meshed depending on the wavelet finite element, the node displacement of the gate rotor wavelet finite element model is expressed by using wavelet function as interpolate function. The displacement of the wavelet element is expressed in Equation 9 (Ma et al., 2003): 


$$
\overrightarrow{\mathrm{u}}=\vec{\varphi} \overrightarrow{\mathrm{a}}^{\mathrm{e}}=\sum_{\mathrm{i}, \mathrm{j}, \mathrm{k}=0}^{\mathrm{N}-2} \phi_{\mathrm{i}}(\varepsilon) \phi_{\mathrm{j}}(\eta) \phi_{\mathrm{k}}(\mu) \overrightarrow{\mathrm{a}}^{\mathrm{e}}
$$

Where:

$$
\overrightarrow{\mathrm{u}}=\left(\begin{array}{c}
\mathrm{u}(\mathrm{x}, \mathrm{y}, \mathrm{z}, \mathrm{t}) \\
\mathrm{v}(\mathrm{x}, \mathrm{y}, \mathrm{z}, \mathrm{t}) \\
\mathrm{w}(\mathrm{x}, \mathrm{y}, \mathrm{z}, \mathrm{t})
\end{array}\right), \overrightarrow{\mathrm{a}}^{\mathrm{e}}=\left(\begin{array}{c}
\mathrm{a}_{1} \\
\mathrm{a}_{2} \\
\vdots \\
\mathrm{a}_{\mathrm{n}}
\end{array}\right), \mathrm{a}_{\mathrm{i}}=\left(\begin{array}{c}
\mathrm{u}_{\mathrm{i}}(\mathrm{t}) \\
\mathrm{v}_{\mathrm{i}}(\mathrm{t}) \\
\mathrm{w}_{\mathrm{i}}(\mathrm{t})
\end{array}\right),(\mathrm{i}=1,2, \cdots, \mathrm{n})
$$

According to the equilibrium equation and boundary condition of the static problem, the equivalent integral form satisfying the Galerkin theory is expressed in Equation 10 (He and Ren, 2012):

$$
\begin{aligned}
& \int_{V e}\left[\rho\left(\frac{\partial \mathrm{W}}{\partial \mathrm{x}} \frac{\partial \overrightarrow{\mathrm{u}}}{\partial \mathrm{x}}+\frac{\partial \mathrm{W}}{\partial \mathrm{y}} \frac{\partial \overrightarrow{\mathrm{u}}}{\partial \mathrm{y}}+\frac{\partial \mathrm{W}}{\partial \mathrm{z}} \frac{\partial \overrightarrow{\mathrm{u}}}{\partial \mathrm{z}}\right)+\mathrm{W} \mu \frac{\partial \overrightarrow{\mathrm{u}}}{\partial \mathrm{t}}\right] \mathrm{dV} \\
& -\int_{\mathrm{Ve}} \frac{\partial \overrightarrow{\mathrm{u}}_{\overrightarrow{\mathrm{n}}}}{\partial \mathrm{n}} \overrightarrow{\mathrm{f}}_{\mathrm{n}} \mathrm{dV}-\int_{\mathrm{Se}} \frac{\partial \overrightarrow{\mathrm{u}}}{\partial \mathrm{n}} \overrightarrow{\mathrm{T}}_{\mathrm{n}} \mathrm{dS}=0
\end{aligned}
$$

where, $\vec{f}_{n}$ denotes body force, $\vec{T}_{n}$ denotes surface force, $\mathrm{W}$ denotes weight function, the interpolate function can used as weight function directly and the following equation will be obtained in Equation 11:

$$
\mathrm{W}_{\mathrm{l}, \mathrm{m}, \mathrm{n}}=\phi_{\mathrm{l}}(\mathrm{x}) \phi_{\mathrm{m}}(\mathrm{y}) \phi_{\mathrm{n}}(\mathrm{z})=\Phi_{1, \mathrm{~m}, \mathrm{n}}
$$

Substituting Equation 9 and 10 into Equation 11 can get the Equation 12:

$\overrightarrow{\mathrm{M}}^{\mathrm{e}} \frac{\mathrm{d}^{2} \overrightarrow{\mathrm{a}}^{\mathrm{e}}}{\mathrm{dt}^{2}}+\overrightarrow{\mathrm{K}}^{\mathrm{e}} \overrightarrow{\mathrm{a}}^{\mathrm{e}}=\overrightarrow{\mathrm{Q}}^{\mathrm{e}}$

where, $\vec{a}^{\mathrm{e}}$ denotes the differential quotient vector of the wavelet coefficients, $\overrightarrow{\mathrm{M}}^{\mathrm{e}}$ denotes the mass matrix, $\overrightarrow{\mathrm{K}}^{\mathrm{e}}$ denotes the stiffness matrix, $\overrightarrow{\mathrm{Q}}^{\mathrm{e}}$ denotes the column vector. The components of $\overrightarrow{\mathrm{M}}^{\mathrm{e}}, \overrightarrow{\mathrm{K}}^{\mathrm{e}}, \overrightarrow{\mathrm{Q}}^{\mathrm{e}}$ are expressed in Equation 13 to 15 (Lilliam et al., 2008):

$$
\begin{aligned}
& \overrightarrow{\mathrm{M}}_{\mathrm{l}, \mathrm{m}, \mathrm{n}, \mathrm{i}, \mathrm{i}, \mathrm{k}, \mathrm{k}}^{\mathrm{e}}=\int_{\mathrm{Ve}} \rho \Phi_{1, \mathrm{~m}, \mathrm{n}} \Phi_{\mathrm{i}, \mathrm{j}, \mathrm{k}} \mathrm{dV} \\
& \overrightarrow{\mathrm{K}}_{\mathrm{m}, \mathrm{n}, \mathrm{li} \mathrm{i}, \mathrm{j}, \mathrm{k}}^{\mathrm{e}}= \\
& \int_{\mathrm{Ve}} \rho\left(\frac{\partial \Phi_{1, \mathrm{~m}, \mathrm{n}}}{\partial \mathrm{x}} \frac{\partial \Phi_{\mathrm{i}, \mathrm{j}, \mathrm{k}}}{\partial \mathrm{x}}+\frac{\partial \Phi_{1, \mathrm{~m}, \mathrm{n}}}{\partial \mathrm{y}} \frac{\partial \Phi_{\mathrm{i}, \mathrm{j}, \mathrm{k}}}{\partial \mathrm{y}}+\frac{\partial \Phi_{1, \mathrm{~m}, \mathrm{n}}}{\partial \mathrm{z}} \frac{\partial \Phi_{\mathrm{i}, \mathrm{j}, \mathrm{k}}}{\partial \mathrm{z}}\right) \mathrm{dV} \\
& \overrightarrow{\mathrm{Q}}_{\mathrm{m}, \mathrm{n}, \mathrm{l}}^{\mathrm{e}}=\int_{\mathrm{Ve}} \overrightarrow{\mathrm{f}}_{\mathrm{n}} \Phi_{\mathrm{m}, \mathrm{n}, \mathrm{l}} \Phi_{\mathrm{i}, \mathrm{j}, \mathrm{k}} \mathrm{dV}-\int_{\mathrm{Se}} \overrightarrow{\mathrm{T}}_{\mathrm{n}} \Phi_{\mathrm{m}, \mathrm{n}, 1} \Phi_{\mathrm{i}, \mathrm{j}, \mathrm{k}} \mathrm{dS}
\end{aligned}
$$

The element matrix is superimposed and the boundary condition is handled and the constant differential equation using node displacement as unknown variable is established in Equation 16:

$\overrightarrow{\mathrm{M}} \frac{\mathrm{d}^{2} \overrightarrow{\mathrm{a}}}{\mathrm{dt}^{2}}+\overrightarrow{\mathrm{K}} \overrightarrow{\mathrm{a}}=\overrightarrow{\mathrm{Q}}$

In the same way, the vibration formula of gate rotor shaft with the multi-cracks can be obtained as Equation 17:

$\overrightarrow{\mathrm{M}} \frac{\mathrm{d}^{2} \overrightarrow{\mathrm{a}}}{\mathrm{dt}^{2}}+\overrightarrow{\mathrm{K}}^{\prime} \overrightarrow{\mathrm{a}}=\overrightarrow{\mathrm{Q}}$

where, $\vec{K}^{\prime}$ denotes the stiffness of the gate rotor without crack.

The natural frequency of the gate rotor shaft with multi-cracks or without crack can be calculated based on Equation 18a and b:

$\left|\overrightarrow{\mathrm{K}}-\omega_{\mathrm{i}}^{2} \overrightarrow{\mathrm{M}}\right|=0$

$\left|\overrightarrow{\mathrm{K}}^{\prime}-\omega_{\mathrm{i}}^{\prime 2} \overrightarrow{\mathrm{M}}\right|=0$

where, $\omega_{i}$ and $\omega_{i}^{\prime}$ denote the natural frequencies of the gate rotor shaft with multi-cracks and without crack respectively, $\mathrm{i}=1,2, \ldots$

For the gate rotor shaft with multi-cracks, the changing rate of the $r$ th step natural frequency is expressed in Equation 19 (Chasalevris and Papadopoulos, 2008):

$\frac{\Delta \omega_{\mathrm{r}}}{\omega_{\mathrm{r}}}=2 \sum_{\mathrm{i}=1}^{\mathrm{I}} \mathrm{g}_{\mathrm{r}}\left(\beta_{\mathrm{i}}\right) \frac{1}{\mathrm{Kt}_{\mathrm{i}}}=2 \int_{\Omega} \mathrm{g}_{\mathrm{r}}\left(\beta_{\mathrm{i}}\right) \mathrm{d} \beta \frac{1}{\mathrm{~K}_{\mathrm{e}}}$

where, $\mathrm{i}$ enotes the number of the crack, $\mathrm{i}=1,2, . . \mathrm{I}$ and $\mathrm{K}_{\mathrm{e}}$ denotes the equivalent stiffness of the crack and $\mathrm{Kt}_{\mathrm{i}}$ denotes the equivalent of $\mathrm{I}$ th crack and $\Omega$ denotes solving space of the damage element and the function $\mathrm{g}_{\mathrm{r}}$ $\left(\beta_{\mathrm{i}}\right)$ can be obtained through solving the $\mathrm{r}$ th modal shape of the gate rotor without crack based on strain energy density and $\mathrm{g}_{\mathrm{r}}\left(\beta_{\mathrm{i}}\right)$ can be expressed in Equation 20 (Fan and Sheng, 2004):

$$
\mathrm{g}_{\mathrm{r}}\left(\beta_{\mathrm{i}}\right)=\frac{\left[\Psi_{\mathrm{r}}\left(\beta_{\mathrm{i}}\right)\right]^{2}}{\mathrm{C}_{\mathrm{r}}}
$$

where, $\Psi_{\mathrm{r}}\left(\beta_{\mathrm{i}}\right)$ denotes the $\mathrm{r}$ th step modal shape. $\mathrm{C}_{\mathrm{r}}$ is expressed in Equation 21: 
$\mathrm{C}_{\mathrm{r}}=4\left(\frac{\sin \gamma_{\mathrm{r}} \cosh \gamma_{\mathrm{r}}-\sinh \gamma_{\mathrm{r}} \cos \gamma_{\mathrm{r}}}{\cos \gamma_{\mathrm{r}}+\cosh \gamma_{\mathrm{r}}}\right)$

where, $\gamma_{\mathrm{r}}$ is the solution of the equation $1+\cos \gamma_{\mathrm{r}} \cosh \gamma_{\mathrm{r}}=0$.

The variation of the stiffness of $r$ th step modal is expressed in Equation 22 to 24:

$\Delta \mathrm{K}=\mathrm{K}-\mathrm{K}^{\prime}$

$\mathrm{K}_{\mathrm{r}}=\int_{0}^{1} \mathrm{EI}(\beta)\left[\Psi_{\mathrm{r}}^{\prime \prime}(\beta)\right]^{2} \mathrm{~d} \beta$

$\mathrm{K}_{\mathrm{r}}=\int_{0}^{1} \mathrm{EI}^{\prime}(\beta)\left[\Psi_{\mathrm{r}}^{\prime \prime}(\beta)\right]^{2} \mathrm{~d} \beta$

where, $\Psi_{\mathrm{r}}^{\prime \prime}(\beta)$ denotes curvature of the main modal shape for $i$ th step modal.

Substituting Equation 22 to 24 into $\frac{\Delta \omega_{\mathrm{r}}}{\omega_{\mathrm{r}}}=\frac{\Delta \mathrm{K}_{\mathrm{r}}}{2 \mathrm{~K}_{\mathrm{r}}}$, the following equation is expressed in Equation 25 (Mira and Gopalakrishnan, 2005):

$$
\frac{\Delta \omega_{\mathrm{r}}}{\omega_{\mathrm{r}}}=\frac{1}{2}\left(\frac{\Delta \mathrm{I}}{\mathrm{I}}\right)_{\mathrm{e}} \frac{\int_{\Omega}\left|\Psi_{\mathrm{r}}^{\prime \prime}(\beta)\right|^{2} \mathrm{~d} \beta}{\int_{0}^{1}\left|\Psi_{\mathrm{r}}^{\prime \prime}(\beta)\right|^{2} \mathrm{~d} \beta}
$$

where, $\Delta \mathrm{I}_{\mathrm{e}}$ is expressed in Equation 26:

$$
\Delta \mathrm{I}_{\mathrm{e}}=\int_{0}^{1}\left[\mathrm{I}(\beta)-\mathrm{I}^{\prime}(\beta)\right] \mathrm{d} \beta
$$

The whole structure is divided into 11 zones and every zone is meshed by several wavelet finite elements and the Equation 27 is obtained according to Equation 19 (Pati and Maiti, 2003):

$$
\frac{\Delta \omega_{\mathrm{r}}}{\omega_{\mathrm{r}}}=2 \sum_{\mathrm{j}=1}^{11} \mathrm{~h}_{\mathrm{r}}(\mathrm{j}) \frac{1}{\left(\mathrm{~K}_{\mathrm{e}}\right)_{\mathrm{j}}}
$$

where, $h_{r}(j)$ is calculated according to Equation 28:

$$
h_{r}(j)=\int_{\Omega_{j}} g_{r}(\beta) d \beta
$$

where, $r$ denotes the $r$ th step modal and the $j$ denotes the $\mathrm{j}$ th element and the solving domain is expressed by $\Omega_{\mathrm{j}}$.

When the changing rates of the mth step natural frequencies are known, the linear equation can be expressed in Equation 29 (Nahvi and Jabbari, 2005):

$$
\frac{\Delta \omega}{\omega_{\mathrm{m} \times 1}}=2 \overrightarrow{\mathrm{H}}_{\mathrm{m} \times \mathrm{n}} \overrightarrow{\mathrm{S}}_{\mathrm{n} \times 1}
$$

where, the element $h_{i, j}$ of the effect coefficient matrix $\overrightarrow{\mathrm{H}}$ is expressed in Equation 30:

$$
h_{i, j}(j)=\int_{\Omega_{j}} g_{i}(\beta) d \beta
$$

The element $s_{j}$ of the damage coefficient matrix $\vec{S}$ is expressed in Equation 31 (Sekhar, 2008):

$$
\mathrm{s}_{\mathrm{j}}=\frac{1}{\left(\mathrm{~K}_{\mathrm{e}}\right)_{\mathrm{j}}}
$$

\subsection{Frequency test of the Gate Rotor Shaft Based on Blind Source Separation Algorithm}

In linear theory, the natural frequencies do not change so much due to cracks that do not change the support condition. In order to improve the correctness of fault diagnosis when the noise is considered, the blind separation algorithm is applied in the frequency test of the gate rotor shaft.

\subsection{The Basic Model of Blind Source Separation}

The blind source separation is a means of processing signal, which was established by Jutten and Herault in 1986 based on neutral network and Hebb study rule. The blind source separation technology can be used for the blind separation of mixed independent signals. The following equation is used to describe the blind separation problem, which is expressed in Equation 32:

$x(t)=A \cdot e(t)$

where, $\mathrm{x}(\mathrm{t})$ denotes $\mathrm{m}$ dimension measured data vector, $x(t)=\left[x_{1}(t), \ldots x_{m}(t)\right]^{T} ; A$ denotes the $m \times n$ dimension mixed matrix; $\mathrm{e}(\mathrm{t})$ denotes the $\mathrm{n}$ dimension vector including $n$ signals, $e(t)=\left[e_{1}(t), \ldots e_{n}(t)\right]^{T}$. The basic task of the blind source separation is to obtain the separation matrix $\mathrm{E}$ and the source signals is separated from the measured signals, which is expressed in Equation 33:

$y(t)=E \cdot x(t)$

$y(t)$ hopes to be approximated to $e(t)$. The mixed matrix $\mathrm{A}$ is used as a compensation of unknown 
signals; the following assumptions can be reached (Delvecchio and Antoni, 2012):

- $m \geq n$

- The source signal $\mathrm{e}(\mathrm{t})$ is independent.

- The blind source separation based on the particle swarm optimization algorithm

The particle swarm optimization is a parallel search algorithm which was established by Kennedy and Eberhart (1995). The location and speed of $i$ th particle can be expressed in Equation 34 and 35:

$$
\begin{gathered}
\mathrm{X}_{\mathrm{i}}=\left(\mathrm{x}_{\mathrm{i} 1}, \mathrm{x}_{\mathrm{i} 2}, \mathrm{x}_{\mathrm{i} 3}, \cdots \mathrm{x}_{\mathrm{in}}\right) \\
\mathrm{V}_{\mathrm{i}}=\left(\mathrm{v}_{\mathrm{i} 1}, \mathrm{v}_{\mathrm{i} 2}, \mathrm{v}_{\mathrm{i} 3}, \cdots \mathrm{v}_{\mathrm{in}}\right)
\end{gathered}
$$

The individual extreme value of ith particle in particle swarm is expressed in Equation 36:

$$
P_{i}=\left(p_{i 1}, p_{i 2}, p_{i 3}, \cdots p_{\text {in }}\right)
$$

The global extreme value of particle swarm is expressed in Equation 37:

$$
\mathrm{P}_{\mathrm{g}}=\left(\mathrm{p}_{\mathrm{g} 1}, \mathrm{p}_{\mathrm{g} 2}, \mathrm{p}_{\mathrm{g} 3}, \cdots \mathrm{p}_{\mathrm{gn}}\right)
$$

The location and speed of the particle can change according to Equation 38 and 39:

$$
\begin{aligned}
& v_{i j}^{t+1}=\omega v_{i j}^{t}+c_{1} \text { rand } . \\
& \left(P_{i j}^{t}-x_{i j}^{t}\right)+c_{2} \text { rand } \cdot\left(P_{g j}^{t}-x_{i j}^{t}\right) \\
& x_{i j}^{t+1}=x_{i j}^{t}+v_{i j}^{t}
\end{aligned}
$$

where, $\mathrm{t}$ denotes the number of generation, $\mathrm{c}_{1}$ and $\mathrm{c}_{2}$ denote the study factors, $c_{1}, c_{2} \in[0,2]$, rand denotes value between 0 and $1, \omega$ denotes the inertial weight value.

In order to reduce the possibility of sinking into local optimization, when optimal information of swarm come to a standstill, the part of swarm will be reinitialized and the activity of the warm can be ensured. The gradient information is introduced to affect the update of speed of particle. When the speed and location of particle is updated at a time, the replacement of every particle can be carried out in probability $\mathrm{P}$ according to formula (38) and (39) and the update will be carried out in probability $1-p$ and the moving step can be confirmed by a linear searching in the negative gradient direction.

The separation objective function is listed in Equation 40:

$$
\mathrm{K}(\mathrm{y})=\sum_{\mathrm{i}=1}^{\mathrm{n}}\left|\mathrm{E}\left(\mathrm{y}_{\mathrm{i}}^{4}\right)-3\right|
$$

The signal is Gauss distribution when the kurtosis equal to zero, the signal is super Gauss distribution when the kurtosis is greater than zero and the signal is sub Gauss distribution when the kurtosis is less than zero. Therefore the blind separation is reached when the kurtosis is greatest for super Gauss signal and the blind separation is reached when the kurtosis is lest for sub Gauss signal.

The main steps of blind separation based on the particle swarm optimization algorithm are listed as follows:

- The signals are obtained and sampled and the centralizing and pre-whitening are carried out for them

- Every particle is initialized within limits, the number of particles is defined as $\mathrm{n}$ and the $\mathrm{n}$ initial solutions and initial speeds generate randomly

- According to the present location and speed of the particle, the new location of each particle generates based on gradient formula

- Signal separation is carried out according to the location of the particle and the centralizing and pre-whitening are carried out for separation signals and the fitness of each particle is computed according to formula (40)

- If the fitness of the particle is superior to the extremes of original individuality for each particle, the present fitness is defined as the extremes of individuality and the global extreme is found out according to the extreme of individuality

- The replacement of each particle can be carried out in probability $\mathrm{P}$ according to formula (38) and (39) and the update will be carried out in probability 1-p and the moving step can be confirmed by a linear searching in the negative gradient direction

- Go to loop, when the iteration times come to the preset value and the optimal output is obtained, End

In order to verify the correctness of the blind separation method, the natural frequencies of torsion vibration of a shaft a cantilever are measured when the noise is considered and the calculating model of the shaft is shown in Fig. 2. A fixed-free boundary condition supports the shaft.

The measured signals are processed by blind separation technology and the corresponding calculating results are obtained and the natural frequencies of torsion vibration of the shaft are calculated according to the torsion vibration theory and the comparing results are listed in Table 1. 


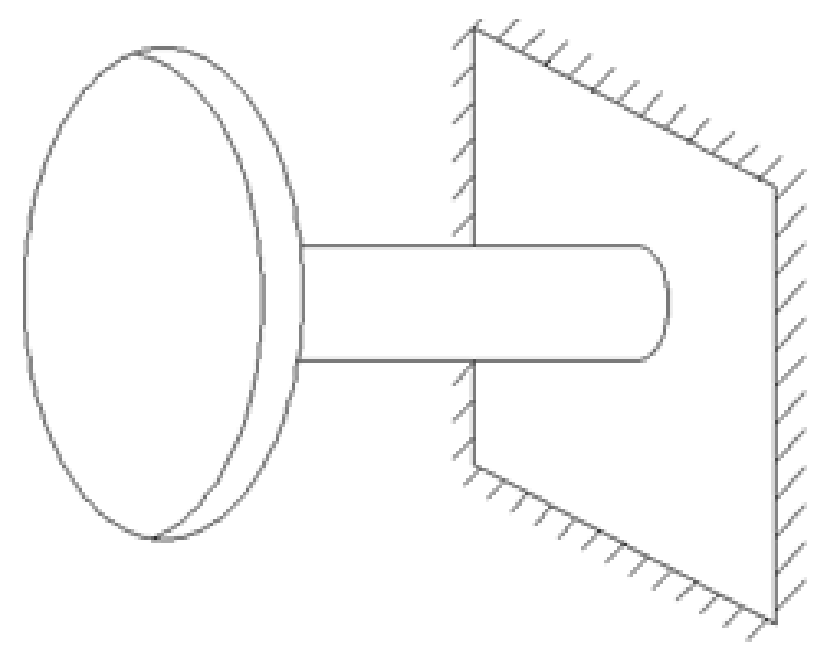

Fig. 2. The diagram of the torsion shaft

Table 1. The comparing results of the natural frequencies of the cantilever

\begin{tabular}{llll}
\hline Order & $\begin{array}{l}\text { Theory } \\
\text { solution/Hz }\end{array}$ & $\begin{array}{l}\text { Blind separation } \\
\text { solution/Hz }\end{array}$ & Error (\%) \\
\hline 1 & 6.78 & 6.85 & 0.10 \\
2 & 15.39 & 15.68 & 0.19 \\
3 & 29.14 & 29.48 & 0.12 \\
4 & 35.46 & 35.79 & 0.09 \\
5 & 55.28 & 55.83 & 0.10 \\
\hline
\end{tabular}

It can be seen from Table 1 that the blind separation method can obtain the precious results when the measured noise is considered.

\subsection{The Identification Procedure of the Multiple Cracks of the Gate Rotor Shaft}

The identification procedure of the multiple cracks of the gate rotor shaft is established based on the wavelet finite element method and the identification procedure is listed as follows.

The changing rate of the natural frequency $\frac{\Delta \omega}{\omega_{\mathrm{m} \times 1}}$ through actual measuring and processing based on the blind separation technology computed and the effect matrix $\overrightarrow{\mathrm{H}}$ of the gate rotor shaft with multiple cracks is calculated by interpolate and then the matrix $\frac{\Delta \omega}{\omega_{\mathrm{m} \times 1}}$ and the $\vec{H}$ are substituted into Equation 29 and the damage coefficient matrix $\vec{D}$ is obtained, where the number of the non-zero element of the matrix $\vec{D}$ can predict the number of the cracks and the element corresponding to the non zero includes the cracks.

Then the value of the element $d_{j}$ which is less than zero is disposed. The physical significance of the positive value of the element $d_{j}$ indicates that the modulus of the section decreases and the physical significance of the negative value indicate that the modulus of the section increases, but it is impossible for the modulus of the section to increase. Therefore the element corresponding to the negative value of $d_{j}$ is intact and $d_{j}$ is assumed to be equal to zero and the damage coefficient matrix of the gate rotor shaft is calculated again and the value of the all the elements of matrix $\vec{D}$ is negative value and the calculation is end.

Then the damage element corresponding to $d_{j}>0$ is disposed and the element will be refined and the effect matrix $\overrightarrow{\mathrm{H}}$ can be calculated again, through this iteration the new damage matrix can be obtained, this procession is repeated and ended until the size of the refined element satisfies the predefined precision and the cracks will be found out according to the damage coefficient finally.

The depths of the cracks are identified. The damage corresponding to coefficients the top three step natural frequencies will be calculated and used as input parameters of the contour lines; and the contour lines corresponding to the every step modal frequency and the intersections of the contour lines are the location and depth of the crack.

\subsection{Quantitative Identification Database of the Crack for the Gate Rotor Shaft}

The plane structural diagram of the gate rotor shaft is shown in Fig. 3. The thickness of the gate rotor shaft is denoted by $\mathrm{h}, \mathrm{h}=4 \mathrm{~mm}$ and the teeth width of the gate rotor shaft is denoted by $b, b=20 \mathrm{~mm}$ and the outer radius of the gate rotor shaft is denoted by $\mathrm{R}_{0}, \mathrm{R}_{0}=70 \mathrm{~mm}$ and the radius on the chamber of the teeth is expressed by $R_{m}, R_{m}=40$ $\mathrm{mm}$, the radius of the inner hole is denoted by $R_{i}, R_{i}=25$ $\mathrm{mm}$. The gate rotor shaft is manufactured by HT250, the elastic modulus is denoted by $\mathrm{E}, \mathrm{E}=210 \mathrm{e} 9 \mathrm{GPa}$ and the Poisson ratio is denoted by $\mathrm{v}, \mathrm{v}=0.29$ and the density is denoted by $\rho, \rho=7800 \mathrm{~kg} / \mathrm{mm}^{3}$. The depth of the crack is denoted by $\delta, \delta=4 \mathrm{~mm}$, which is equal to the thickness of the gate rotor. There are two cracks existing in the gate rotor shaft tooth and the crack is shown in Fig. 3.

Based on the blind source separation with the particle swarm optimization algorithm, the natural frequencies are obtained. The natural frequencies of intact and cracked gate rotor shaft are listed in Table 2. The part of the gate rotor shaft tooth is divided into 11 zones and every zone is meshed by 108 wavelet finite elements and the wavelet finite element division is shown in Fig. 4.

The consistent meshing technique is used to ensure the results can be trusted and the mesh size is reduced in the vicinity of the crack for every cycle and the curved boundary is meshed curved finite elements and straight line elements. 
Table 2. The top six natural frequencies of the intact and cracked gate rotor shaft $(\mathrm{Hz})$

\begin{tabular}{lllllll}
\hline Natural frequency & 1 step & 2 step & 3 step & 4 step & 6 step & 6 step \\
\hline Intact $\omega_{\mathrm{i}}$ & 10.319 & 24.004 & 59.036 & 89.207 & 116.327 & 180.312 \\
cracked $\omega_{\mathrm{i}}^{\prime}$ & 9.852 & 23.039 & 58.388 & 88.516 & 115.684 & 179.618 \\
\hline
\end{tabular}

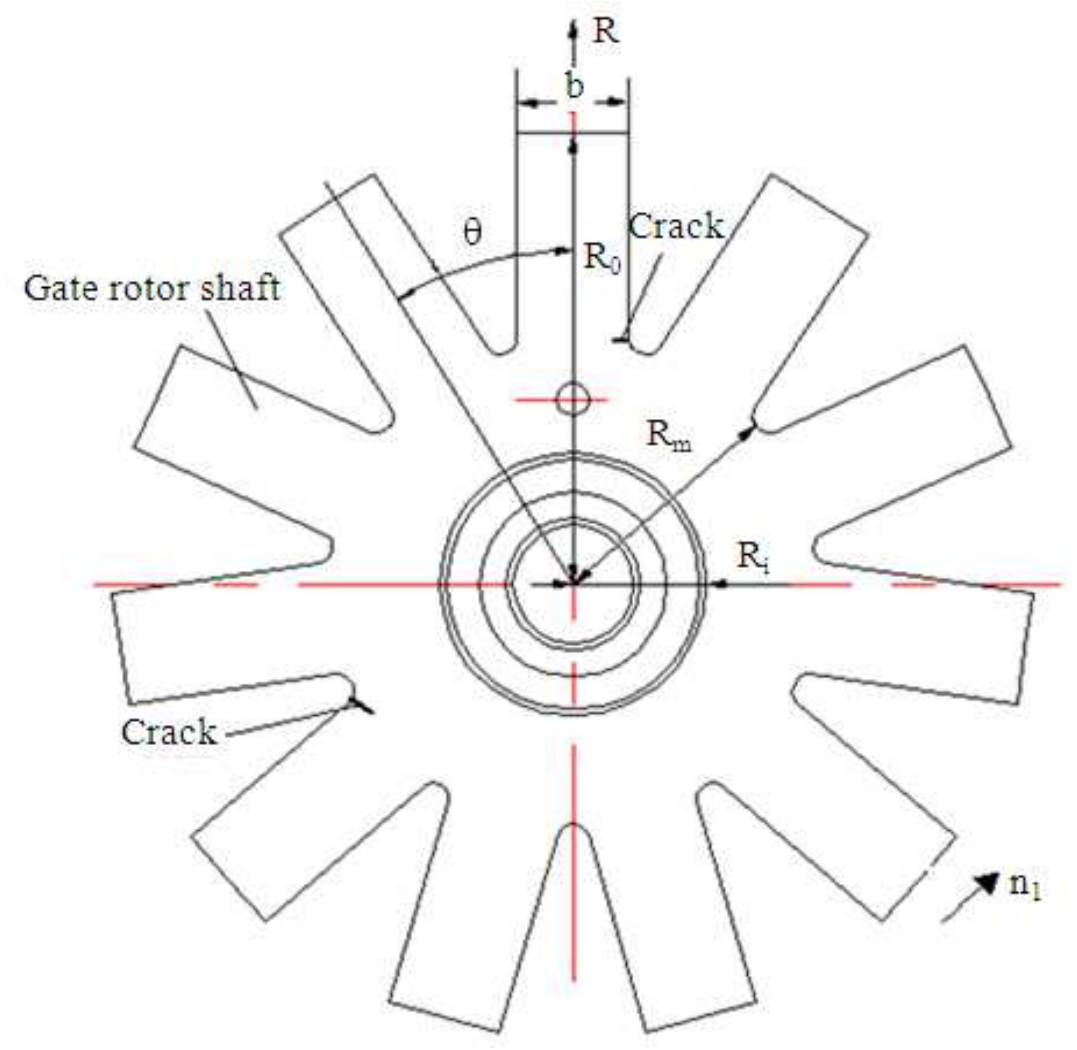

Fig. 3. The plane structure diagram of gate rotor shaft

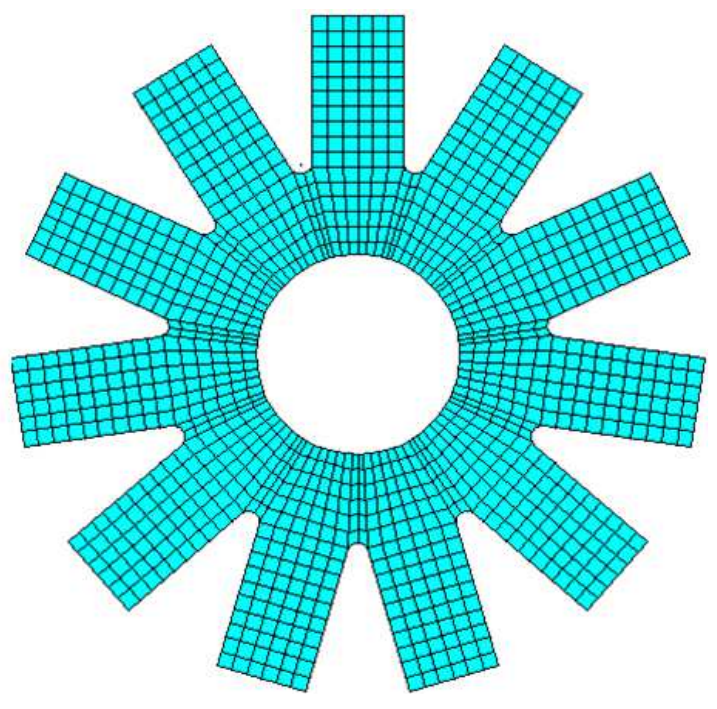

Fig. 4. The diagram of the first mesh of the part of the gate rotor shaft teeth
When the Equation 20 is substituted into Equation 25 and the effect coefficient matrix $\overrightarrow{\mathrm{H}}$ can get and according to the data in Table 1 and the following formula can be expressed in Equation 41:

$$
\frac{\Delta \omega}{\omega_{6 \times 1}}=2 \overrightarrow{\mathrm{H}}_{6 \times 11} \overrightarrow{\mathrm{D}}_{11 \times 1}
$$

The damage coefficient vector $\left[\mathrm{d}_{1}, \mathrm{~d}_{2}, \mathrm{~d}_{3}, \ldots, \mathrm{d}_{11}\right]^{\mathrm{T}}$ can be obtained through solving the Equation 32, which is listed as follows:

$$
\begin{aligned}
& \overrightarrow{\mathrm{D}}=\left[\mathrm{d}_{1}, \mathrm{~d}_{2}, \mathrm{~d}_{3}, \mathrm{~d}_{4}, \mathrm{~d}_{5}, \mathrm{~d}_{6}, \mathrm{~d}_{7}, \mathrm{~d}_{8}, \mathrm{~d}_{9}, \mathrm{~d}_{10}, \mathrm{~d}_{11}\right]^{\mathrm{T}} \\
& =[0.0004,0.0034, \\
& -0.0012,0.0025,0,0,0,0,0.0029,-0.0001,0.0003]^{\mathrm{T}}
\end{aligned}
$$

where, $d_{3}$ and $d_{9}$ are less than zero and they are set as zero and the formula (32) is solved again and the new damage coefficients are obtained as follows: 


$$
\begin{aligned}
& \overrightarrow{\mathrm{D}}=\left[\mathrm{d}_{1}, \mathrm{~d}_{2}, \mathrm{~d}_{4}, \mathrm{~d}_{5}, \mathrm{~d}_{10}, \mathrm{~d}_{11}\right]^{\mathrm{T}} \\
& =[-0.00041,-0.0034,0.0012,-0.0025,-0.0029,0.0003]^{\mathrm{T}}
\end{aligned}
$$

where, $\mathrm{d}_{1}, \mathrm{~d}_{2}, \mathrm{~d}_{5}$ and $\mathrm{d}_{10}$ are less than zero and they are set as zero and the following results are as follows:

$$
\begin{aligned}
& \overrightarrow{\mathrm{D}}=\left[\mathrm{d}_{4}, \mathrm{~d}_{11}\right]^{\mathrm{T}} \\
& =[0.0011,0.0002]^{\mathrm{T}}
\end{aligned}
$$

According to the final results, the elements of the damage matrix are all positive value, therefore the zones $\Sigma_{\mathrm{e} 4}$ and $\Sigma_{\mathrm{e} 11}$ can be predicted as cracked elements.

The cracked zones $\Sigma_{\mathrm{e} 4}$ and $\Sigma_{\mathrm{e} 11}$ are extracted and they are divided into three zones respectively and element division in two zones is carried out again and the wavelet finite element meshes are shown in Fig. 5.

The element effect matrix of $\overrightarrow{\mathrm{H}}_{\sum \mathrm{e}_{4}}$ and $\overrightarrow{\mathrm{H}}_{\sum \mathrm{e}_{11}}$ is obtained through interpolating in the solving domain and the new response matrix $\overrightarrow{\mathrm{H}}_{1}$ can be obtained through combining $\overrightarrow{\mathrm{H}}_{\sum \mathrm{e}_{4}}$ with $\overrightarrow{\mathrm{H}}_{\sum \mathrm{e}_{11}}$ and the damage coefficients matrix can be expressed as follows:

$$
\begin{aligned}
& \vec{D}=\left[d_{11}, d_{12}, d_{13}, d_{14}, d_{15}, d_{16}\right]^{T} \\
& =[-0.022,0.3249,-0.0235,0.0493,0.0594,0.0291]^{T}
\end{aligned}
$$

and the element which is neglect value can be set as zero and the new damage coefficient matrix can be expressed as follows:

$$
\overrightarrow{\mathrm{D}}_{1}=\left[\mathrm{d}_{12}, \mathrm{~d}_{15}\right]^{\mathrm{T}}=[0.084,0.014]^{\mathrm{T}}
$$

The precision error is set as $\xi=1^{0}$ and the same procedure is re-executed as follows.

\section{Cycle 1:}

The wavelet finite element model of the gate rotor shaft is shown in Fig. 6:

$$
\overrightarrow{\mathrm{D}}_{2}=\left[\mathrm{d}_{22}, \mathrm{~d}_{27}\right]^{\mathrm{T}}=[0.1744,0.4214]^{\mathrm{T}}
$$

\section{Cycle 2:}

The meshing situation is shown in Fig. 7:

$$
\overrightarrow{\mathrm{D}}_{3}=\left[\mathrm{d}_{32}, \mathrm{~d}_{35}\right]^{\mathrm{T}}=[0.6484,0.9454]^{\mathrm{T}}
$$

The zones $\Sigma_{\mathrm{e} 32}$ and $\Sigma_{\mathrm{e} 32}$ are predicted as cracked element and the angle is less than the error and the iteration ends and then the precious location and the identification of the depth is carried out according to the contour line method.
The damage parameters are defined as $\overrightarrow{\mathrm{D}}_{3}=[0,0.6484,0,0,0,0]^{\mathrm{T}}$ for zone $\Sigma_{\mathrm{e} 32}$, which are substituted into formula (32) and the changing rate of the natural frequencies of the multi-cracked gate rotor shaft $\frac{\Delta \omega_{\mathrm{r}}}{\omega_{\mathrm{r}}}$ corresponding to $\vec{D}_{3}$ and the results are listed as follows:

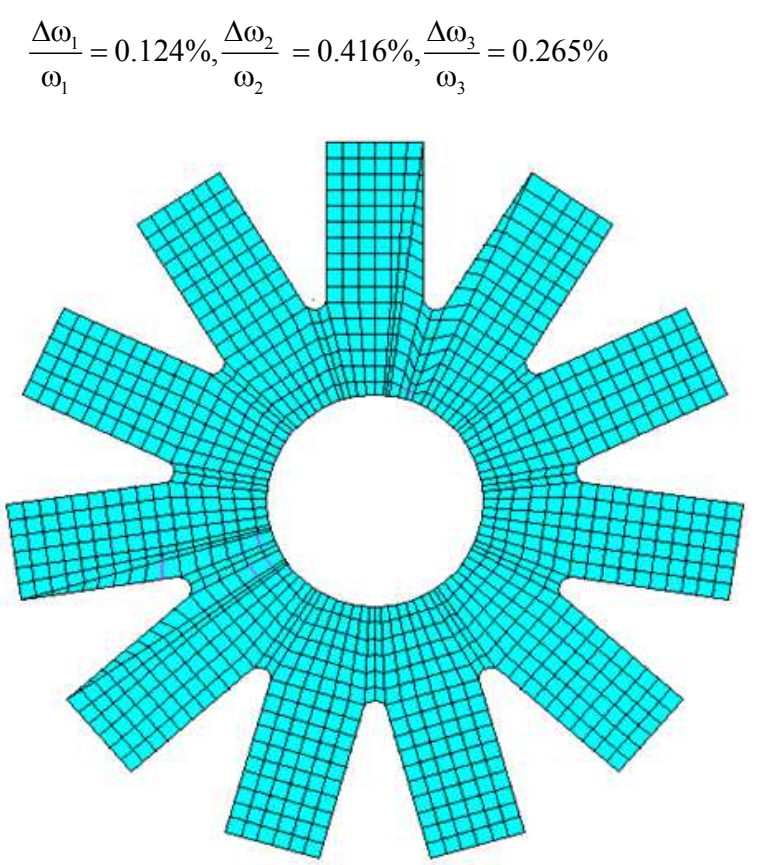

Fig. 5. The diagram of the mesh of cycle one for the part of the gate rotor shaft teeth

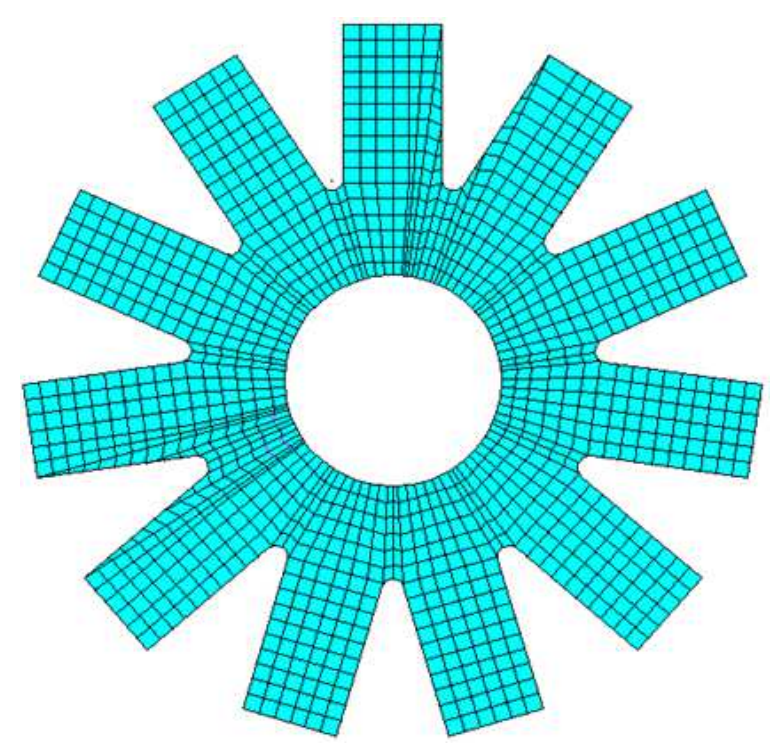

Fig. 6. The diagram of the mesh of cycle two for the part of the gate rotor shaft teeth 


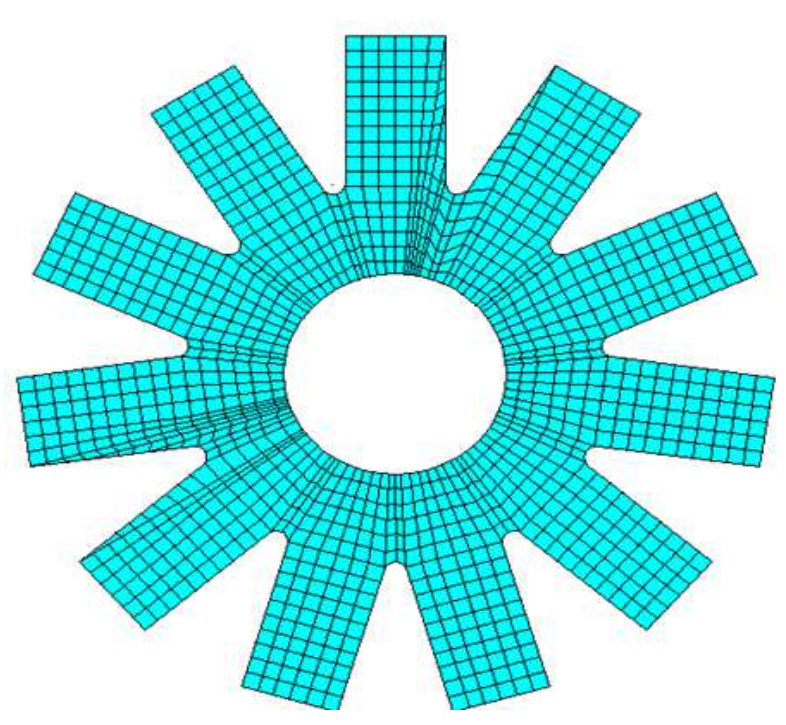

Fig. 7. The diagram of the mesh of cycle three for the part of the gate rotor shaft teeth

The crack identification of the gate rotor shaft can be carried out according to the variety of the natural frequencies of the gate rotor with multi-cracks. According to the formulas (17) and (18), the changing rate of the top step natural frequencies corresponding to cracks with different location and depth is calculated and the quantitative recognition database of the crack for the gate rotor shaft can be acquired and the following relational formula can be expressed in Equation 42:

$$
\frac{\Delta \omega_{\mathrm{r}}}{\omega_{\mathrm{r}}}=\mathrm{F}_{\mathrm{j}}(\mathrm{w}, \theta), \mathrm{j}=1,2,3
$$

where, w denotes the relative depth of the crack, $\mathrm{w}=\frac{1}{\mathrm{~b}}, \theta$ denotes the relative position of the crack, $\theta=\frac{\alpha}{2 \pi}$, fi, denotes the frequency of the gate rotor with the crack, $f_{j}=\frac{\omega_{i}}{2 \pi}$.

The curve surface of the changing rate for the natural frequency can be obtained through curved surface fitting of the calculating data and the quantity identification database of the multi-cracks can be established and the crack identification database is shown in Fig. 8. Figure 8a shows the fitting surface of the function $\frac{\Delta \omega_{1}}{\omega_{1}}$ and Fig. $8 \mathbf{b}$ shows the fitting surface of the function $\frac{\Delta \omega_{2}}{\omega_{2}}$ and Fig. 8b shows the fitting surface of the function $\frac{\Delta \omega_{3}}{\omega_{3}}$.

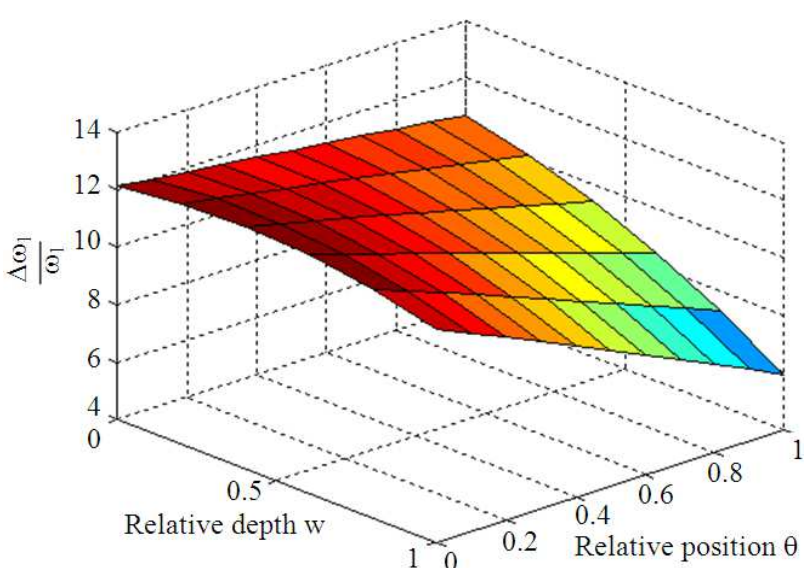

(a)

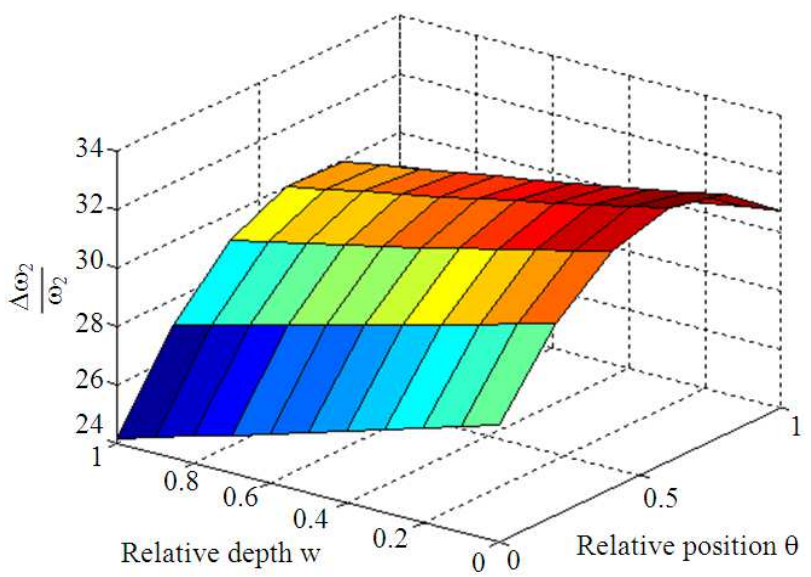

(b)

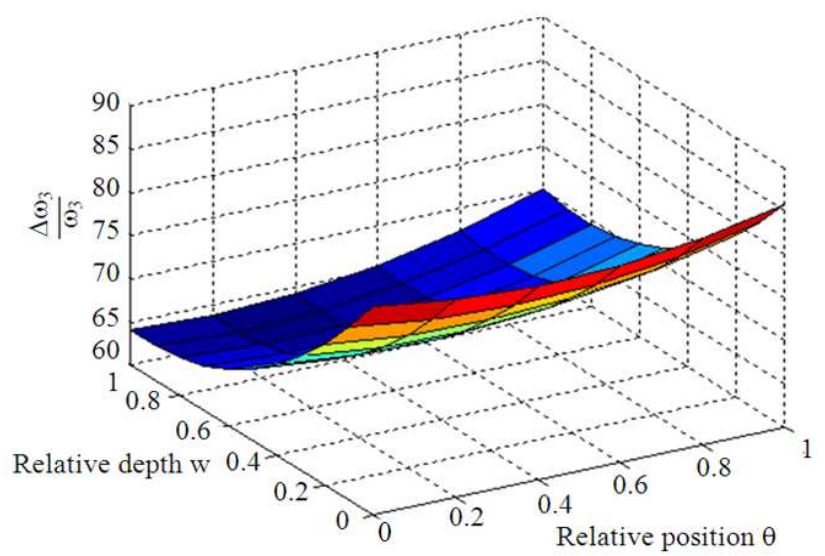

(c)

Fig. 8. The curve surface of the changing rate of the natural frequency (a) The first modal (b) The second (c) The third modal modal

The quantity identification of the crack can be achieved after the database of the multi-cracks is established. 
Table 3. The results of crack identification

\begin{tabular}{|c|c|c|c|c|c|c|}
\hline \multirow{2}{*}{$\begin{array}{l}\text { The number } \\
\text { of the crack }\end{array}$} & \multicolumn{3}{|c|}{ Relative depth w } & \multicolumn{3}{|c|}{ Relative position $\theta$} \\
\hline & Actual value & Predicting value & Error $(\%)$ & Actual value & Predicting value & Error $(\%)$ \\
\hline 1 & 0.0548 & 0.0539 & 1.64 & 0.95 & 0.9501 & 0.01 \\
\hline 2 & 0.0859 & 0.0855 & 0.47 & 0.27 & 0.2698 & 0.07 \\
\hline
\end{tabular}

$\frac{\Delta \omega_{1}}{\omega_{1}}, \frac{\Delta \omega_{2}}{\omega_{2}}$ and $\frac{\Delta \omega_{3}}{\omega_{3}}$ are input into the database and the relative depth $\mathrm{w}$ and the relative position $\theta$ of the crack can be confirmed according to the curve surface of the natural frequencies confirmed above and the crack identification results are listed in Table $\mathbf{3}$ and the results show that this method can identify the location and depth of the multi-cracks for the gate rotor shaft correctly. The location and depth of zone $\Sigma_{\mathrm{e} 35}$ can be obtained by the same procedure.

\section{CONCLUSION}

The wavelet finite element is applied to have fault diagnosis for the gate rotor shaft with multi-cracks and the intact and cracked wavelet finite element are established respectively and the corresponding vibration equations are established. The identification procedure of the gate rotor shaft with the multiple cracks is established and the gate rotor with two different cracks is predicted according to this method and results show that the predicting value is closer to the actual value and the wavelet finite element method is a good technology for identifying the multi-cracks of the gate rotor shaft of the single screw compressor.

\section{ACKNOWLEDGMENT}

This research was supported by the national natural science foundation (51206075).

\section{REFERENCES}

Chasalevris, A.C. and C.A. Papadopoulos, 2008. Coupled horizontal and vertical bending vibrations of a stationary shaft with two cracks. J. Sound Vibrat., 309: 507-528. DOI: 10.1016/j.jsv.2007.07.039

Chen, X.F., S.J. Yang and J.X. Ma, 2004. The construction of wavelet-finite element and its application. Finite Elem. Anal. Design, 40: 541-554. DOI: $10.1016 / \mathrm{S} 0168-874 \mathrm{X}(03) 00077-5$

Delvecchio, S. and J. Antoni, 2012. Extraction of angle deterministic signals in the presence of stationary speed fluctuations with cyclostationary blind source separation. Mech. Syst. Signal Proc., 27: 350-361. DOI: 10.1016/j.ymssp.2011.09.009
Fan, S.C. and N. Sheng, 2004. Mesh less formulation using NURBS basis functions for eigenfrequency changes of beam having multiple open cracks. J. Sound Vibrat., 269: 781-793. DOI: 10.1016/S0022460X(03)00134-2

He, W.Y. and W.X. Ren, 2012. Finite element analysis of beam structures based on trigonometric wavelet. Finite Elem. Anal. Des., 51: 59-66. DOI: 10.1016/j.finel.2011.11.005

Kennedy, J. and R. Eberhart, 1995. Particle swarm optimization. Proceedings of the IEEE International Conference on Neural Networks, Nov. 27-Dec. 01, IEEE Xplore Press, Perth, WA., pp: 1942-1948. DOI: $10.1109 /$ ICNN.1995.488968

Lilliam, A.D., T.M. Maria and V. Victoria, 2008. Daubechies wavelet beam and plate finite elements. Finite Elem. Anal. Des., 45: 200-209. DOI: 10.1016/j.finel.2008.09.006

Liu, Y.N., Y.H. Liu and Z.Z. Cen, 2008. Daubechies wavelet meshless method for 2-D elastic problems. Tsinghua Sci. Technol., 25: 605-608. DOI: 10.1016/S1007-0214(08)70096-8

Ma, J.X., J.J. Xue and S.G. Yang, 2003. A study of the construction and application of a Daubechies wavelet-based beam element. Finite Elem. Anal. Des., 39: 965-975. DOI: 10.1016/S0168874X(02)00141-5

Mira, M. and S. Gopalakrishnan, 2005. Spectrally formulated wavelet finite element for wave propagation and impact force identification in connected 1-D waveguides. Int. J. Solids Struct., 42: 4695-4721. DOI: 10.1016/j.ijsolstr.2005.02.007

Nahvi, H. and M. Jabbari, 2005. Crack detection in beams using experimental modal data and finite element model. Int. J. Mech. Sci., 47: 1477-1497. DOI: 10.1016/j.ijmecsci.2005.06.008

Pati, D.P. and S.K. Maiti, 2003. Detection of multiple cracks using frequency measurements. Eng. Fracture Mech., 70: 1553-1572. DOI: 10.1016/S00137944(02)00121-2

Sekhar, A.S., 2008. Multiple cracks effects and identification. Mech. Syst. Signal Proc., 22: 845878. DOI: $10.1016 /$ j.ymssp.2007.11.008 
Bin Zhao / American Journal of Engineering and Applied Sciences 6 (3): 309-319, 2013

Xiang, J.W., Y. Liu, X.F. Chen, X. Chenb and Z. Heb, 2009. A wavelet finite element method for the analysis of rortor-bearing systems. J. Vibrat. Eng., 22: 406-412. DOI: 10.1016/j.finel.2009.09.001 